\title{
Study of Microstructure and Mechanical Behavior of Aluminum/Garnet/Carbon Hybrid Metal Matrix Composites (HMMCs) Fabricated by Chill Casting Method
}

\author{
M. G. Anantha Prasad ${ }^{1}$, Nityanand Bandekar ${ }^{2}$ \\ ${ }^{1}$ Centre for Emerging Technologies, Jain University, Bangalore, India \\ ${ }^{2}$ S.D.M. Institute of Technology, Ujire, India \\ Email: ${ }^{*}$ ananthaprasad1210@yahoo.com
}

Received 17 February 2015; accepted 8 March 2015; published 12 March 2015

Copyright (C) 2015 by authors and Scientific Research Publishing Inc.

This work is licensed under the Creative Commons Attribution International License (CC BY). http://creativecommons.org/licenses/by/4.0/

(c) (;) Open Access

\section{Abstract}

HMMCs are significantly influenced by the reinforcements. Composites with two or more reinforcements and finer grain structures are extensively used due to improved mechanical and tribological properties. The evolution of finer and uniform microstructures is strongly dependent on the cooling rate during solidification. In this investigation stir cast hybrid composites of aluminum alloy LM13 was fabricated with garnet and carbon particulate reinforcements. Chills of various materials such as copper, steel, iron and silicon carbide was used to accelerate the solidification. Combination of dispersoid varies from $3 \mathrm{wt} \%$ to $12 \mathrm{wt} \%$ in steps of $3 \mathrm{wt} \%$ garnet and $3 \mathrm{wt} \%$ carbon particulates. Microstructure characterization and mechanical properties such as hardness and ultimate tensile strength of reinforced hybrid composites were examined. The test specimens are prepared and tested as per American society for testing and materials (ASTM) standard. Vickers hardness measurement was carried out to study the hardness of the composite. The effect of chill and reinforcement characteristics was presented and compared with the hybrid composite without chill material. The results confirm the positive relationship between mechanical behavior and the dispersiod content. The copper chill cast composite with $9 \mathrm{wt} \%$ garnet and $3 \mathrm{wt} \%$ carbon was found to increase mechanical properties.

\section{Keywords}

Aluminum, Chill Casting, Garnet, Hardness, Microstructure, Stir Casting

\footnotetext{
${ }^{*}$ Corresponding author.
}

How to cite this paper: Prasad, M.G.A. and Bandekar, N. (2015) Study of Microstructure and Mechanical Behavior of Aluminum/Garnet/Carbon Hybrid Metal Matrix Composites (HMMCs) Fabricated by Chill Casting Method. Journal of Materials Science and Chemical Engineering, 3, 1-8. http://dx.doi.org/10.4236/msce.2015.33001 


\section{Introduction}

The search for new and improved materials and processes goes on continuously for a multitude of applications. Higher temperature materials, higher strength-to-weight ratio materials, highly corrosion-resistant materials have attracted a great deal of attention from scientists and engineers all over the world. Aluminum Composite materials have been considered the "material of choice" in some applications of the automotive and aircraft industries by delivering high-quality surface finish, styling details, and processing options [1]. Improvement of mechanical and tribological properties of aluminum can be achieved through creating hybrid composites with two or more types of reinforcements. Hybrid composites have improved strength, increased wear resistance, low density, corrosion resistance and high stiffness over metal matrix composites. Cooling conditions during solidification strongly influence the evolution of finer grain structure in the composites [2]. Volumetric Heat Capacity (VHC) of various chill materials does significantly affect the strength, fracture toughness and microstructure of the hybrid composites [3] [4]. Microshrinkage or dispersed porosity in the composite can be minimized by judicious location of chills.

An improvement in the tribological properties of Aluminum HMMCs has been successfully attained by introducing ceramic particles, such as $\mathrm{SiC}, \mathrm{B}_{4} \mathrm{C}, \mathrm{Al}_{2} \mathrm{O}_{3}$ and TiC [5] [6] using different routes, such as stir-casting, squeeze casting, in-situ and powder metallurgy [7] [8]. By adding the ceramic reinforcement problem of machinability occurs. To improve machinability, the graphite is added to matrix materials which reduce mechanical (hardness) properties. However, the application of Garnet is rarely found in the literature.

Joel Hemanth [9] investigated the effect of reinforcement and chilling on strength, hardness and wear behavior of aluminum based metal matrix hybrid cast composites reinforced with kaolinite $\left(\mathrm{Al}_{2} \mathrm{SiO}_{5}\right)$ and carbon $(\mathrm{C})$ particulates. It is discovered that chilled HMMCs with $\mathrm{Al}_{2} \mathrm{SiO}_{5}-9 \% / \mathrm{C}-3 \%$ dispersoid content proved to be the best in enhancing the mechanical and wear properties. Joel Hemanth [10] described production and mechanical properties of chilled aluminum-quartz composite that can cast using metallic and nonmetallic chill blocks. The composite developed is shown to provide significant weight savings and improved mechanical properties. Leela B. N. et al. [11] studied microstructure and microhardness of chill cast $\mathrm{Al}-\mathrm{B}_{4} \mathrm{C}$ composites. The use of end chills during casting not only favours directional solidification but also accelerates solidification. S. Soleymani et al. [12] investigated the effect of $\mathrm{SiC}$ and $\mathrm{MoS}_{2}$ particles on microstructural and tribological properties of Al5083 based surface hybrid composite produced by friction stir processing. P. Ravindran et al. [13] have studied the influence of $5 \mathrm{wt} \% \mathrm{SiC}$ and $\mathrm{X}$ wt\% graphite (X = 5 and 10) on microstructure and mechanical properties of $\mathrm{Al} 2024$ hybrid composite produced using powder metallurgy technique. Prashant Sharma [14] have reported on the influence of SiC particulate and E-glass fiber reinforcements on fabrication and mechanical testing of Aluminum 6061 hybrid composite. N. Radhika et al. [15] fabricated hybrid composite of aluminum alloy reinforced with alumina and graphite by stir casting process. Investigation showed an increasing trend in hardness and impact strength values with increase in weight fraction of alumina. With the increase in the demand for high performance composites, in the present investigation carbon is added which acts as solid lubricant improves tribological properties. But presence of carbon reduces mechanical properties, hence Garnet reinforced which is one of the hardest naturally available ceramic material.

\section{Experimental Work}

\subsection{Materials}

\subsubsection{Aluminum Alloy LM13}

Aluminum is the third most abundant chemical element in the earth's crust. In this work Aluminum LM13 is chosen as a matrix for its light weight. The broad use of aluminum alloys is dictated by a very desirable combination of properties, combined with the ease with which they may be produced in a great variety of forms. The chemical composition of matrix material is shown in Table 1.

\subsubsection{Garnet}

Garnets are a group of silicate minerals that have been used as gemstones and abrasives. Garnet helps to control the mechanical behavior of the Earth's crust, mantle, and transition zone because of garnet's inferred high strength in comparison with the other mineral components. Table 2 shows the chemical composition of garnet. 


\subsubsection{Chill Materials}

Volumetric heat capacity of various chill materials improves the microstructure of cast composite. Table 3 shows the thermo-physical properties of chill materials.

\subsection{Chill Casting Procedure}

The present investigation aims at producing cast aluminum alloy-garnet-carbon particulate composites in moulds containing copper, steel, iron and silicon carbide end chills by dispersing garnet-carbon particles in molten aluminum alloy above the liquidus temperature. Commercially available Aluminum alloy LM13 material is used and melted in a resistance furnace at around $750^{\circ} \mathrm{C}$; Garnet and carbon particulates were preheated to $700^{\circ} \mathrm{C}$.

A stir casting process is used to fabricate hybrid composites reinforced with various weight fractions of garnet and carbon particulates. Properties of garnet are Density $=4.19 \mathrm{~kg} / \mathrm{m}^{3}$, Hardness $=7.8$ Mohs. Figure 1 shows a sectional view of the stir casting arrangement. Combination of dispersoid varies from $3 \mathrm{wt} \%$ to $12 \mathrm{wt} \%$ in steps of $3 \mathrm{wt} \%$ of garnet and $3 \mathrm{wt} \%$ Carbon particulates. Reinforcements were introduced evenly into the molten metal alloy by means of feeding attachments. The size of garnet and carbon particulates dispersed is between 30 and $80 \mu \mathrm{m}$. Meanwhile, the molten HMMCs was well agitated by means of a mechanical mixing which was carried out for about $15 \mathrm{~min}$ at an average mixing speed of $760 \mathrm{rpm}$. The melt was next poured into a sand mold with a chill

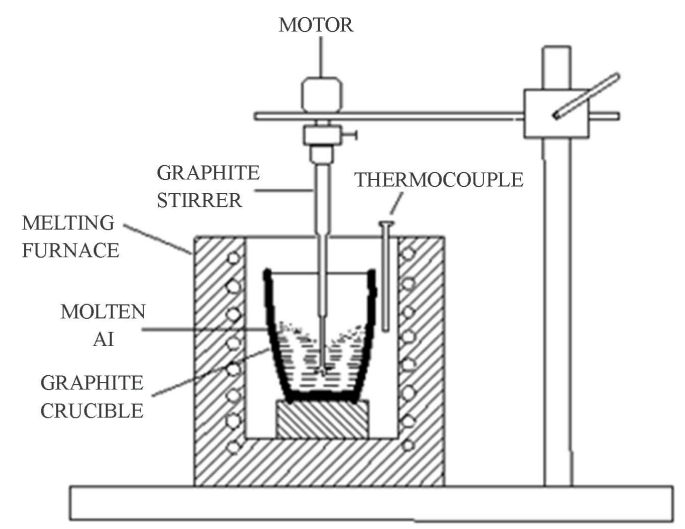

Figure 1. Stir casting setup.

Table 1. Chemical composition of matrix material (Al-alloy LM13).

\begin{tabular}{cccccccc}
\hline Elements & $\mathrm{Zn}$ & $\mathrm{Mg}$ & $\mathrm{Si}$ & $\mathrm{Fe}$ & $\mathrm{Mn}$ & $\mathrm{Ni}$ & $\mathrm{Al}$ \\
\hline \% by wt & 0.5 & 1.4 & 12.0 & 1.0 & 0.5 & 1.5 & Balance \\
\hline
\end{tabular}

Table 2. Chemical composition of garnet.

\begin{tabular}{ccccccccc}
\hline Elements & $\mathrm{Al}$ & $\mathrm{Al}_{2} \mathrm{O}_{3}$ & $\mathrm{Fe}$ & $\mathrm{FeO}$ & $\mathrm{Si}$ & $\mathrm{SiO}_{2}$ & $\mathrm{O}$ \\
\hline \% by wt & 10.84 & 20.48 & 33.66 & 43.30 & 16.93 & 36.21 & 38.57 \\
\hline
\end{tabular}

Table 3. Thermo physical properties of chill materials.

\begin{tabular}{cccc}
\hline Types of chill material & Density $\mathrm{kg} / \mathrm{m}^{3}$ & Thermal conductivity $\mathrm{W} / \mathrm{mK}$ & Specific heat $\mathrm{J} / \mathrm{kgK}$ \\
\hline Copper & 8.80 & 380 & 151 \\
Steel & 7.61 & 52 & 55 \\
Iron & 7.80 & 40 & 47.5 \\
Silicon carbide & 3.21 & 120 & 750 \\
\hline
\end{tabular}


attached to it at one end. Different molds are prepared with different chill materials like copper, steel, iron and silicon carbide.

The same type of mold was used to sand-cast a specimen in which case no chill was used. The chills were of $150 \mathrm{~mm}$ long, $35 \mathrm{~mm}$ high and $25 \mathrm{~mm}$ thick in dimension. The moulds produced plate-shaped ingots of dimensions $150 \times 120 \times 25 \mathrm{~mm}$. Moulds were prepared using silica sand with $5 \%$ bentonite as binder and $5 \%$ moisture according to American Foundrymen Society (AFS) standards, and were dried in an air furnace. Figure 2 shows the arrangement of mold used for casting specimens. Specimens for all the tests were selected only at the chill end of the casting and all the specimens were heat-treated by aging before testing. Properties such as hardness, tensile strength of the developed hybrid composites were tested as per ASTM standards.

\section{Results and Discussions}

\subsection{Microscropic Examination}

The mechanical properties of composite materials are strongly dependent on micro structural parameters of the system. The evolution of microstructure depends largely on the cooling rate during phase change. Though the microstructure evolution depends on many process parameters, the final structure is decided by the cooling conditions during solidification [16]. The present investigation aims at producing cast aluminum alloy-garnet-carbon particulate composites in moulds containing copper, steel, iron and silicon carbide end chills by dispersing garnet-carbon particles in molten aluminum alloy above the liquidus temperature. The dispersoid being added ranges from $3 \mathrm{wt} \%$ to $12 \mathrm{wt} \%$ in steps of $3 \mathrm{wt} \%$.

Cast composites with 9 wt\% garnet-3 wt\% carbon exhibits highest values for tensile strength and hardness. Figure 3 shows the optical micrographs of aluminum composites reinforced with 9 wt\% garnet- 3 wt\% carbon with different chill materials. Figure 3(a) shows microstructure of $9 \mathrm{wt} \%$ garnet and $3 \mathrm{wt} \%$ carbon using Copper chill. The volumetric heat capacity (VHC) of the copper chill block not only favors directional solidification but also accelerates solidification. Faster cooling rates give rise to finer structures and improved mechanical properties [17]. Optical micrographs of hybrid composites show clearly the uniform distribution of Garnet and Carbon in the matrix, and no void and discontinuities were observed. There is a good interfacial bonding between the particles and matrix material.

Figure 3(b) shows microstructure of 9 wt\% garnet and 3 wt\% carbon using steel chill. Volumetric heat capacity of $25 \mathrm{~mm}$ thick steel chill is less compared to copper chill. It is observed from these figures that for all the chilled HMMCs there is a uniform distribution of dispersoid and good bonding with the matrix. This is due to gravity of Garnet particulates associated with judicious selection of stirring parameters (vortex route), good wetting of pre heated reinforcement by the matrix melt [10]. Figure 3(c) and Figure 3(d) shows microstructure of 9 wt\% garnet and $3 \mathrm{wt} \%$ carbon using iron and silicon carbide chill respectively. Iron and silicon carbide chills give rise to coarse grain structures. Garnet particulates tend to agglomerate in the matrix in the castings obtained using iron and silicon carbide chills and grain size successively increases. Figures 3(e) shows microstructure of 9 wt\% garnet and $3 \mathrm{wt} \%$ carbon without using chill which gave rise to coarse structure with reduced tensile strength and hardness.

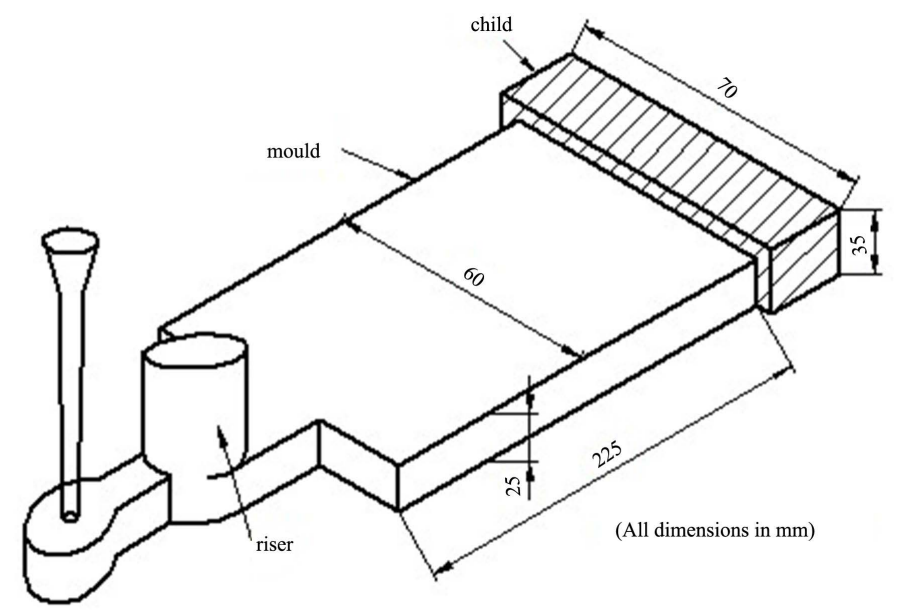

Figure 2. Mold used for casting specimens. 


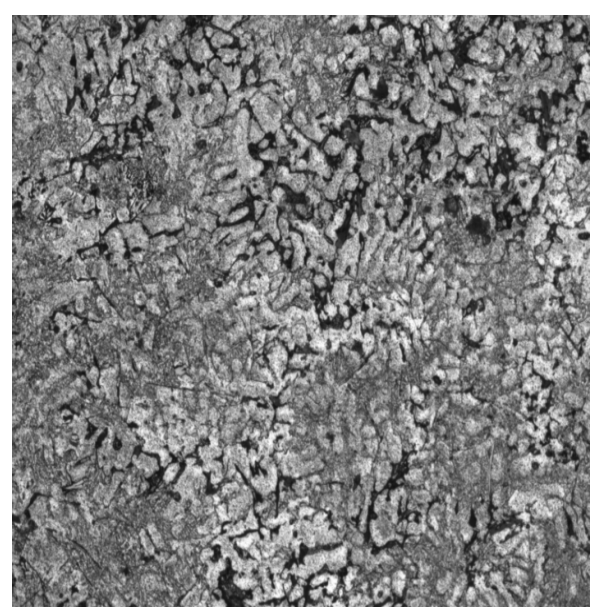

(a)

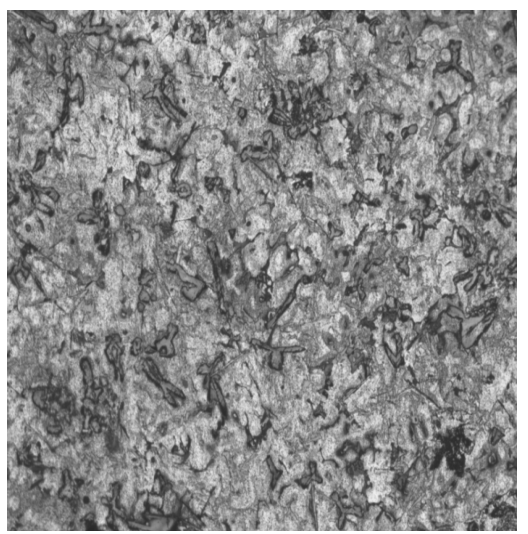

(c)

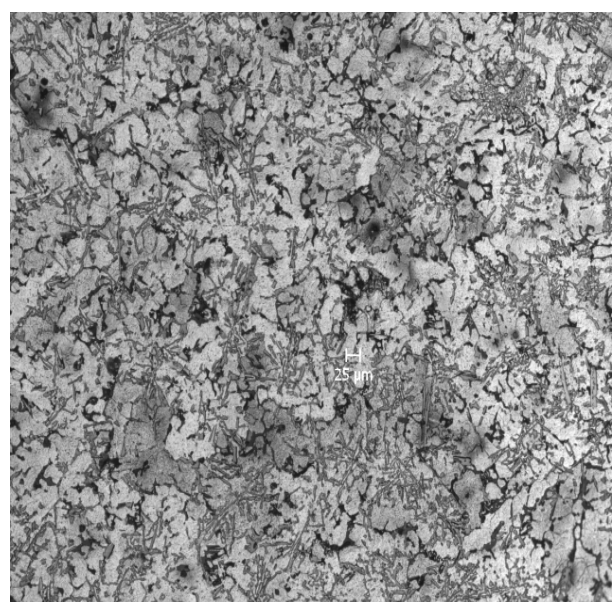

(b)

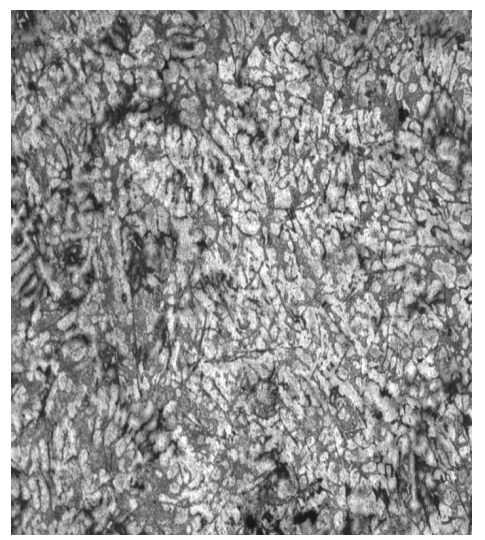

(d)

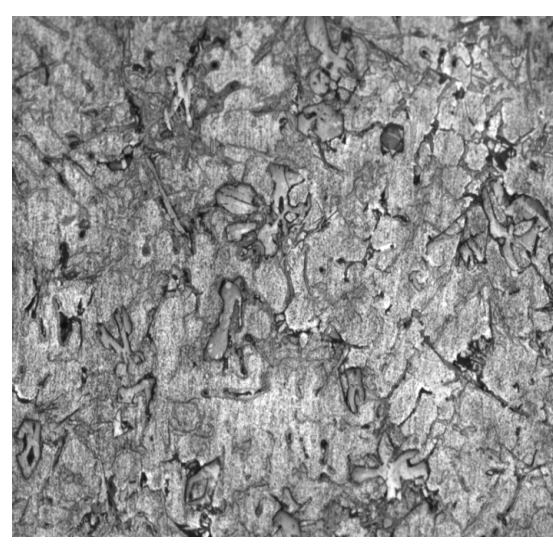

(e)

Figure 3. Microstructure of 9 wt\% garnet-3 wt\% carbon cast composite using various chill material. (a) Copper chill; (b) Steel chill; (c) Iron chill; (d) Silicon carbide chill; (e) Without chill.

\subsection{Ultimate Tensile Strength (UTS)}

To study the tensile behavior of the hybrid composites, specimens were prepared and tested as per ASTM E8M standard. Figure 4 shows the plot of UTS v/s dispersoid content of the HMMCs near the chill end for composites cast using different types of chills of $25 \mathrm{~mm}$ thickness. It is evident from this plot that for a particular chill, the UTS of the composite increases as garnet content is increased up to $9 \%$ by weight, beyond which it drops again. It is evident from these results that the HMMCs with the highest UTS is the one 9 wt\% cast composite with a copper chill, followed by those cast with a steel chill, iron chill, silicon carbide chill and without chill in that order. This is because the copper chill has the highest volumetric heat capacity and hence extracts heat most quickly from the HMMC during casting, followed by steel, iron, silicon carbide and no-chill in that order. The results confirm the positive relationship between UTS and the dispersiod content. There is therefore no advantage in reinforcing the Al matrix with garnet contents above $9 \mathrm{wt} \%$ as far as UTS is concerned.

Figure 5 shows UTS of different cast composites with different chill materials. UTS of 3 wt $\%$ garnet-3 wt $\%$ carbon cast hybrid composite are lower than that of the remaining counterpart. Result shows that tensile strength is highest for the one cast with a copper chill, followed by those cast with a steel chill, iron chill, silicon carbide chill and a no-chill in that order. From the graph it is understood that the tensile strength values of the hybrid composites are higher than that of the remaining counterpart and the combination $9 \mathrm{wt} \%$ garnet and $3 \mathrm{wt} \%$ carbon give superior tensile strength value. The improvement in tensile strength was attributed to presence and uniform distribution reinforcements. The incorporated reinforcements act as barrier to dislocation movements.

The tensile strength of $12 \%$ garnet and 3\% carbon reinforced hybrid composite is actually lesser than that of the hybrid composite reinforced with $9 \%$ garnet and 3\% carbon. The possible reason could be; increased agglo- 


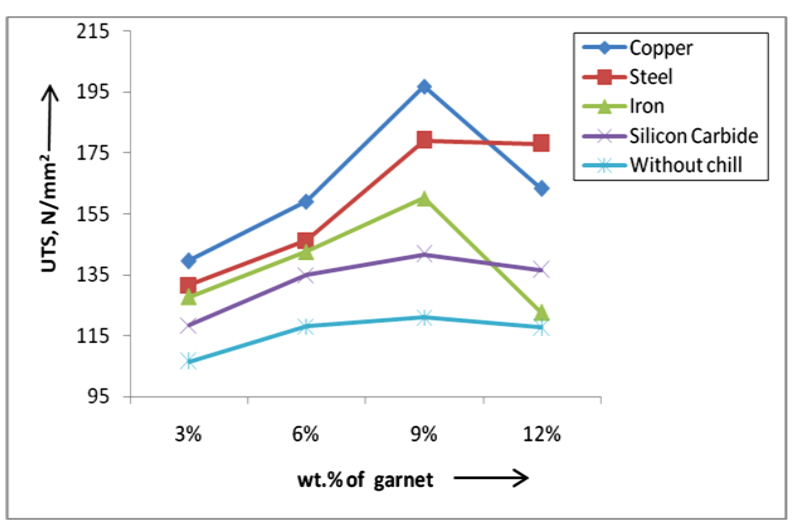

Figure 4. Plot of UTS v/s wt\% of garnet.

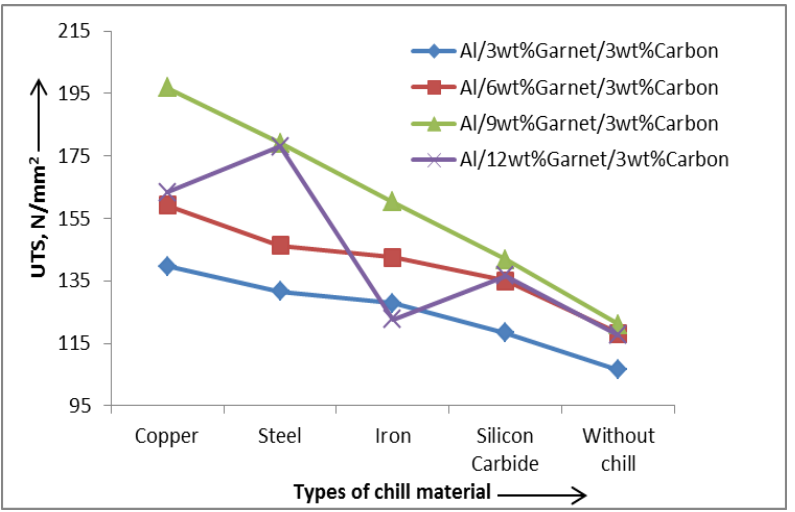

Figure 5. UTS of different cast composites v/s various chill materials.

meration of the reinforced particles and increased porosity content as the particle percentage increases. Agglomeration of particles leads to the microclusters and the loosely packed particles in the clusters makes the material as weaker structure and hence reduction in tensile strength [9]. The presence of porosity in the solidified microstructure reduces the mechanical properties of cast hybrid composites as the plastic deformation is initiated from the voids formed. The large difference in co-efficient of thermal expansion (CTE) mismatch between the aluminum and hybrid reinforcements could actually induces the enormous amount of dislocations in the hybrid composites. These induced dislocations act as a barrier for the dislocations movement. Hence the strength of the hybrid composites are increased significantly even for the addition of very low weight percentage of the reinforcements.

\subsection{Hardness Studies}

Hardness tests were performed on the cast samples with a Vickers hardness testing machine. A precision diamond indenter is impressed on material at a load of 50 grams for 10 secs. Figure 6 shows hardness of chilled HMMCs cast with different wt $\%$ of garnet using various types of chills with different volumetric heat capacity. The results of micro hardness test (HV) conducted on chilled MMCs samples revealed an increasing trend in matrix hardness with an increase in reinforcement content (up to 9 wt\% garnet). Results of hardness measurements also revealed that copper chill has an effect on hardness of the composite.

This significant increase in the hardness can be attributed primarily to presence of harder garnet ceramic particulates in the matrix, a higher constraint to the localized deformation during indentation due to their presence and reduced grain size due to chilling [18] [19]. In ceramic reinforced composite, there is generally a big difference between the mechanical properties of the dispersoid and those of the matrix. These results in incoherence and a high density of dislocations near the interface between the dispersoid and the matrix. Figure 7 shows the 
plot of hardness of composite with various wt $\%$ of dispersiod content which confirms the positive relationship between hardness and the dispersiod content. Hardness of $3 \mathrm{wt} \%$ garnet-3 wt\% carbon cast hybrid composite is lower and increases as garnet content is increased up to $9 \%$ by weight, beyond which it drops again for the one cast with a copper chill, followed by those cast with a steel chill, iron chill, silicon carbide chill and a no-chill in that order. It is evident from the results that copper chill extracts heat most quickly from the HMMC during casting. Hardness values of the hybrid composites are higher than that of the remaining counterpart and the combination $9 \mathrm{wt} \%$ garnet and $3 \mathrm{wt} \%$ carbon give superior hardness value.

The increase in hardness of hybrid composite with the increase in weight percent of reinforcement's upto 9 wt\% garnet is owing to the following reasons 1) high hardness of garnet reinforcement particles; 2) uniform distribution of garnet in the composites; 3) The increased density that contributes to the increase in hardness [10]. Composites with higher hardness could be achieved by this technique which may be due to the fact that garnet and carbon particles act as obstacles to the motion of dislocation.

\section{Conclusions}

- Aluminum matrix garnet-carbon reinforced composites were successfully cast by stir casting route using different end chill materials. From the analysis of the cast specimens the following conclusions can be drawn.

- The chilling effect is optimum in case of copper chill. The chilling effect successively reduces with steel, iron, silicon carbide and composite without using chills. Volumetric heat capacity (VHC) of the chill is found to increase the amount of heat absorbed.

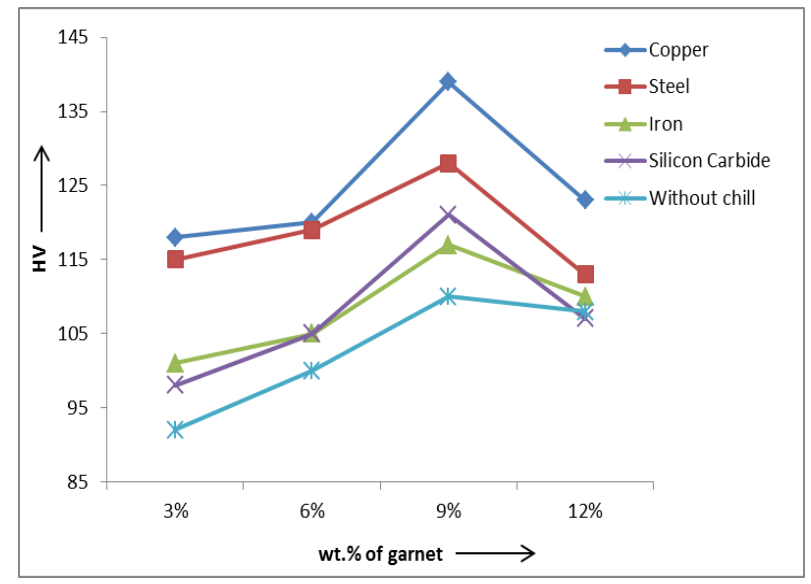

\section{Figure 6. Hardness v/s wt\% of garnet.}

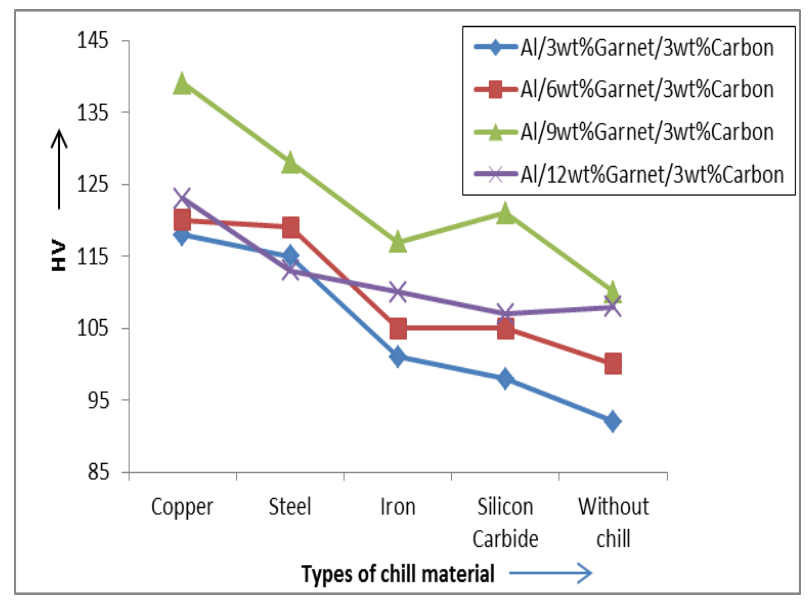

Figure 7. Hardness of various cast composites with different chill materials. 
- Fine grain structure, uniform distribution of dispersoid and good bonding between the matrix and the dispersoid is obtained with the use of copper chill, whereas, the grain size successively increases with the use of steel, iron, silicon carbide and composite without chills.

- Test result showed that these HMMCs were greatly influenced by the dispersiod and different material of chill blocks. Hardness \& UTS of the composite are found to depend on the wt $\%$ of the dispersiod and type of chilling.

A dispersoid content $9 \mathrm{wt} \%$ Garnet $+3 \mathrm{wt} \%$ carbon with copper chill was found to increase the mechanical properties, and therefore, it is considered as the optimum limit.

\section{References}

[1] Kainer, K.U., Ed. (2003) Metal Matrix Composites. Wiley-VCH.

[2] Hemanth, J. (2011) Fracture Behavior of Cryogenically Solidified Aluminum Alloy Reinforced Metal Matrix Composites. JCEMS, 2, 110-111.

[3] Hemanth, J. (2014) Heat Transfer Analysis during External Chilling of Composite Material Castings. Modeling and Numerical Simulation of Material Science, 4, 1-7. http://dx.doi.org/10.4236/mnsms.2014.41001

[4] Veeresh Kumar, G.B., Rao, C.S.P. and Selvaraj, N. (2011) Mechanical and Tribological Behavior of Particulate Reinforced Aluminum Metal Matrix Composites-A Review. JMMCE, 10, 59-32.

[5] Deuis, R.L. and Subramanian, C. (1997) Dry Sliding Wear of Aluminum Composites-A Review. Composites Science and Technology, 57, 415-420. http://dx.doi.org/10.1016/S0266-3538(96)00167-4

[6] Asif, M., Chandra, K. and Misra, P.S. (2011) Development of Aluminum Based Hybrid Metal Matrix Composites for Heavy Duty Applications. JMMCE, 10, 1337-1338.

[7] Umanath, K., Palanikumar, K. and Selvamani, S.T. (2013) Analysis of Dry Sliding Wear Behaviour of Al6061/SiC/ $\mathrm{Al}_{2} \mathrm{O}_{3}$ Hybrid Metal Matrix Composites. Composites: Part B, 53, 159-168. http://dx.doi.org/10.1016/j.compositesb.2013.04.051

[8] Baradeswaran, A. and Perumal, A.E. (2014) Study on Mechanical and Wear Properties of $\mathrm{Al} 7075 / \mathrm{Al}_{2} \mathrm{O}_{3} / \mathrm{Graphite} \mathrm{Hy-}$ brid Composites. Composites: Part B, 56, 136-138.

[9] Hemanth, J. (2011) Finite Element Wear Behavior Modeling of $\mathrm{Al} / \mathrm{Al}_{2} \mathrm{SiO}_{5} / \mathrm{C}$ Chilled Hybrid Metal Matrix Composites (CHMMCs). Materials Sciences and Application, 2, 878-812. http://dx.doi.org/10.4236/msa.2011.27118

[10] Hemanth, J. (2010) Production and Mechanical Properties of Chilled Aluminum-Quartz Castable Particulate Composite. JMEPEG, 10, 143-149. http://dx.doi.org/10.1361/105994901770345141

[11] Leela, B.N. and Sreenivas Rao, K.V. (2012) Microstucture and Microhardness of Chill Cast Al-B ${ }_{4} \mathrm{C}$ Composites. IJMERR, 1.

[12] Soleymani, S., Abdollah-Zadeh, A. and Alidokht, S.A. (2012) Microstructural and Tribological Properties of Al5083 Based Surface Hybrid Composite Produced by Friction Stir Processing. Wear, 278, 41-47.

[13] Ravindran, P., Manisekar, K., Narayanasamy, R. and Narayanasamy, P. (2013) Tribological Behaviour of Powder Metallurgy-Processed Aluminium Hybrid Composites with the Addition of Graphite Solid Lubricant. Ceramics International, 39, 1169-1182. http://dx.doi.org/10.1016/j.ceramint.2012.07.041

[14] Sharma, P. (2012) Determination of Mechanical Properties of Aluminium Based Composites. IJET, 3, 157-152.

[15] Radhika, N., Subramanian, R. and Venkat Prasat, S. (2011) Tribological Behaviour of Aluminium/Alumina/Graphite Hybrid Metal Matrix Composite Using Taguchi’s Techniques. JMMCE, 10, 427-443.

[16] Hemanth, J. (2010) Microstructure, Mechanical Properties and Wear Behavior of Metallic, Nonmetallic and Deep Cryogenically Chilled ASTM A216 WCB Steel. Journal of Alloys and Compounds, 506, 645-647. http://dx.doi.org/10.1016/j.jallcom.2010.07.036

[17] Hemanth, J. (2002) Wear Behavior of Chilled (Metallic and Non-Metallic) Aluminum Alloy-Glass Particulate Composite. Materials and Design, 23, 479-487. http://dx.doi.org/10.1016/S0261-3069(02)00012-2

[18] Hemanth, J. (2000) The Solidification and Corrosion Behavior of Austempered Chilled Ductile Iron. Journal of Materials Processing Technology, 101, 159-166. http://dx.doi.org/10.1016/S0924-0136(00)00424-6

[19] Hemanth, J. (2000) Action of Chills on Soundness and Ultimate Tensile Strength (UTS) of Aluminum-Quartz Particulate Composite. Journal of Alloys and Compounds, 296, 193-200. http://dx.doi.org/10.1016/S0925-8388(99)00528-9 